INTERNATIONAL DESIGN CONFERENCE - DESIGN 2018

https://doi.org/10.21278/idc.2018.0352

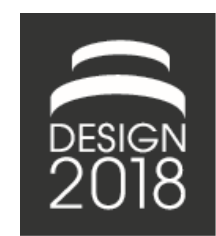

\title{
LEANIFICATION OF THE ENGINEERING PROCESS FOR CUSTOMIZED ROAD SAFETY PRODUCTS
}

\author{
S. Ulonska, T. Welo and T. Rølvåg
}

\begin{abstract}
Increasing need for customization and documentation but with deficits in a systematic product configuration strategy can result in repeated problem-solving and non-value added engineering. This is especially challenging for SMEs where resources are limited. To remain competitive, they need to gather efficient ways of providing engineer-to-order products. This paper presents a case study of the implementation of a customizable product platform combined with a web-based interface in an industrial SME for road safety products as an opportunity to increase customer value and reduce waste.
\end{abstract}

Keywords: lean product development, computational design methods, documentation management, case study

\section{Introduction}

Today's customers and markets demand increased variation and customization. Manufacturing companies without a clear customization strategy spend much time and resources on (re-)engineering products and adapting them to specific customer needs. Even though a company might have developed a similar product before, processes to adapt and change a design are often characterized by high complexity and unclear dependencies. Consequently, engineers struggle to reengineer products efficiently, resulting in resources used for reinventing products, resolving problems and firefighting as well as repeated creation of documentation, instead of using resources on new product development (Kennedy et al., 2013, Haug et al., 2008).

A common countermeasure to this challenge is to employ a generic product structure in form of a modular product platform and realize particular customer orders by instantiating specific values of requirements and constraints (Gunasekaran, 1998, Kristianto et al., 2013, Barros et al., 2014). By implementing such a strategy, the initial engineer-to-order (ETO) customization approach can partly or entirely be turned into a systemized, configure-to-order (CTO) customization approach (Kuroda and Mihira, 2007).

A major development in product customization during the last years has been the heavy use of web-based configurators, which can provide the same advantages of mass-production in configuration as mass customization (MC) (Fogliatto et al., 2012). At a web-page, the customer is allowed to create selfcontained product variants, based on own input that is channelled and processed through predefined algorithms (Perrouin et al., 2016). Once implemented adequately, this may help create a basis for MC, which has become a driver of competitive advantage in several large scale industrial sectors, such as automotive, clothing or computer manufacturing (Salvador et al., 2004).

However, there are many challenges related to implementation of adequate approaches. It requires a strategical realignment of the entire business, including accurate analysis of customer needs, preparation of the current product portfolio in the form of an analysis of products, variants as well as identifying 
potential constraints in the form of manufacturing capabilities, an analysis of related customization cost, and an overall integration of IT capabilities to engineering capabilities. Even though the literature provides a number of methodologies and tools, the implementation is challenging - especially for SME companies where financial resources are limited and the creation of a CTO framework for MC adds an extra work load to already busy workdays (Lovett et al., 2000). Many industry sectors experience the success of online configurators. The existing literature provides a good resource for drawing best practices for implementation strategies such as modularity, product families, embodiment of configurators and detailed design (Ferguson et al., 2014). However, examples usually focus on large scale industries and consumer products and with high complexity. This complexity implies high cost and hiring of IT specialists, which is challenging for SMEs, and which do not have the same financial opportunities (Lovett et al., 2000). Thus, there is a gap in the literature of providing evidence web-based product configurators that can be implemented with relatively simple means, applying commonly available engineering and documentation software tools.

In an attempt explore this topic further, a case study been conducted over a period of three years. The case company, Lattix AS, is an industrial SME that develops, manufactures and tests safety mast systems for traffic and aviation purposes. The products are characterized by high variety and extensive documentation effort to conform with compliance and performance to various national and international safety and quality standards. In order to use engineering resources more effectively, the company chose to implement a webbased product configuration system (DriveWorksPro) for most common road traffic mast systems and integrate this with standard calculation and documentation tools from MS Office.

In this study, we seek to find the answer to the following research question: How can platform-based product architectures and web-based mass-customization tools be applied to increase the competiveness of industrial SMEs and configuration handed to the customers?

This paper presents the results of the implementation of platform-based product architectures and contributes thus to the body of research by providing a real-life example of applying these in an industrial SME context and a conservative market.

\section{Literature review}

The relevant literature covers many research areas, ranging from (systems) engineering, product management, marketing, and economics. However, in this section we focus on the engineering literature. Information has been collected in recent research on lean product development, product standardization and customization, product platforms, knowledge-based engineering (KBE), mass-customization, etc.

\subsection{Mass customization}

A customized product is designed and produced specifically to meet the needs of a particular customer (Mintzberg, 1988). Duray et al. (2000) consider the distinction between product variety and customization as fundamental. Variety provides the customer to choose a certain, preferred product out of a number of similar variants, whereas customization adds the opportunity to specify the product. Thus, customization implies that the customer must be involved in specifying the product. However, a great variety of products may satisfy the customer and may substitute the need for customization. Mintzberg (1988) introduces three forms of customization, including pure, tailored, and standardized customization. A pure customization approach resembles an ETO customization, where products are designed according to certain customer wishes. A tailored customization strategy takes its initiation in a basic design that is modified to meet the specific needs. In a standardized customization strategy, a product is assembled from a predefined set of standard components.

The paradigm of MC emerged in the late 1980's in response to the demand to increase product variety (Pine, 1993) and can be defined as the broad provision of personalized products and services (Davis, 1989). Market segmentation and global competition made the number of varieties offered by consumer product manufacturers to increase significantly during the last two decades and is today applied in many large scale industrial sectors, as e.g. automotive (Hu, 2013). A fundamental principle of $\mathrm{MC}$ is to integrate customers in activities of product specification (Fogliatto et al., 2012). The outcome may be beneficial since it can realize the benefits of mass production in design and engineering and exploit an initial investment over time due to the economies of scale and thus a reduction in cost and lead times even though the initial work 
load is high (Kusiak and Huang, 1996; Duray et al., 2000, Da Cunha et al., 2007, Agard and Bassetto, 2012). Further, it may reduce technical, commercial and financial risks (Sanchez, 2004).

The necessary framework for successful implementation of MC (Fogliatto et al., 2012, Forza and Salvador, 2007) can be summarized into (1) building the product catalog, (2) configuring customer orders, (3) transferring orders to manufacturing, and (4) manufacturing customized orders. Pine (1993) and (Jiao et al., 2003) argue that modularity is a key to achieving this because it provides the means for repetitive production in volume as well as modification and combination of modules for product distinctiveness. Several researchers (Berry et al., 2013, Fogliatto et al., 2012, Forza and Salvador, 2007) discover three main prerequisites for implementing MC: (1) a product architecture with a platform that allows for product compatibility/interchangeability of its functional features or components, (2) is the development of manufacturing machines and systems for fabricating and assembling personalized product features or modules and (3) a network or cyber-infrastructure system facilitating the design, review, analysis, and production of these products, incorporating consumers as appropriate in the process.

\subsection{Product platform}

Product platforms are defined by Meyer and Lehnerd (1997) and Robertson and Ulrich (1998), who describe a product platform as a set of subsystems and interfaces that form a common structure from which a stream of derivate products can be efficiently developed and produced. Thus, the standard modules in the architecture can become a platform across several product deliveries. According to Holland (1992) modules can be configured independently from the platform and be substituted by or changed when desired. When considering customization on base of a product platform, different types of modularity, such as (1) component-sharing, (2) cut-to-fit, (3) mix, and (4) sectional modularity can either be applied separately or combined (Duray et al., 2000). Literature provides different methodologies to implement a modular architecture. One approach embodies qualitative methods, e.g., (Park and Simpson, 2005, Kumar and Allada, 2007), which are based on matrices or algorithms. The other approach uses quantitative methods, e.g., (Stone et al., 2000, Martin and Ishii, 2002, Bruun et al., 2013), which base their (mainly visual) product modelling strategy on experience. Both require analysis of requirements, functions, principal solutions and physical details and their dependencies.

\subsection{Configuration and IT support tools}

IT systems provide means to integrate customers in the production process by product configuration, product specification and co-designing (Piller, 2004). Dietrich et al. (2007) identify two roles of information management in $\mathrm{MC}$ as enablers to:

- fulfil orders correctly by integrating the information flows and;

- construct a database of customer demands and preferences by monitoring the configuration process.

Current software tools provide many possibilities as the dimensioning, mechanical analysis or creation of documentation always with a direct feedback to the customer whether the configuration is suitable to valid rules (Fogliatto et al., 2012). Knowledge Based Engineering (KBE) represents a merging of objectoriented programming, artificial intelligence, and computer aided design. KBE systems aim to capture product and process information to allow businesses to model engineering processes, and then use the model to automate all or part of the process (Lovett et al., 2000). A KBE is a computer representation of the product design process and can contain information on both the product and the processes that is used to create the part. A KBE product model can also use information outside its environment, such as physicsbased analysis, databases, spreadsheets, legacy programs, and cost models (Chapman and Pinfold, 1999). A simpler approach than KBE are "design automation" capabilities that many CAD systems like SolidWorks provide. These systems typically allow parts, assemblies, and drawings to be parametrically varied. However, capabilities for extensive changes to the product configuration are often restricted, and the ability to embed rules is limited to simple logical statements. KBE systems provide far more power and flexibility in the development of design automation systems. However, the implementation time and costs related to a KBE product model is usually too high for SMEs (Lovett et al., 2000). 
Levandowski et al. (2013) argue that no software tool has the perfect fit for all business processes of a company, such that usually a combination of different tools is necessary to satisfy the needs.

Web-based configurators are enablers to increase the use of the IT-tools described above during the last years. At a web-page, the customer is allowed to create self-contained product variants based on own input that is channelled and processed through predefined algorithms (Fogliatto et al., 2012, Perrouin et al., 2016). Systems may be used by customers to analyze alternative customization options, and for purchase decision support, and by companies for pricing, design, production planning, and to gather products' process information (Grenci and Watts, 2007).

\subsection{Conclusion of the literature review}

Literature provides a high density of examples and best practices of implementing MC approaches with respect to process focus. There is significant effort in the engineering and distribution related stages of the embodiment and detailed design as well as manufacturing, sales and distribution or implementation of web-based tool. A challenge less explored, however, is how to apply these with the means of a SME company with limited resources of IT resources for implementation.

\section{Research design}

\subsection{The case company}

The research of this paper has been conducted in form of a case study at Lattix AS, a Norwegian SME manufacturer of aluminium mast systems for road traffic and aviation purpose. The mast constructions are applied as support for signs, traffic information and surveillance systems, as well as aviation systems such as approach lights, radar equipment support, etc. In addition, the company offers different accessories, including connectors, clamps, and ground foundations that are required to provide complete ready-to-install systems. The masts are so-called passive safety masts under the brand name Lattix ${ }^{\circledR}$, which are classified 'non-energy absorbing' and are approved for the highest safety standards in case of collision with vehicles along the roadside or airplanes at airfields. Consequently, there is a vast amount of documentation related to the performance for the mast constructions, in order to ensure compliance to different national and international standards in environmental impacts (e.g. wind loads), road design, crash-tests, etc. To meet the different requirements, the mast systems need to be customized for certain customer needs and adapted to local conditions for each order.

The focus has been on the road traffic product family, which is the product with the highest production volume. In order to justify the effort of implementing a configure-to-order system (Lovett et al., 2000; Fogliatto et al., 2012), the highest potential of gaining benefit of improved customization was expected here. These are sign posts at the road sides with single or multi mast layout, half gantries and gantries (Figure 1).

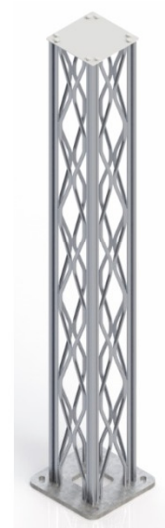

Mast assembly

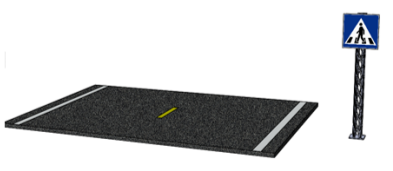

Single signpost layout

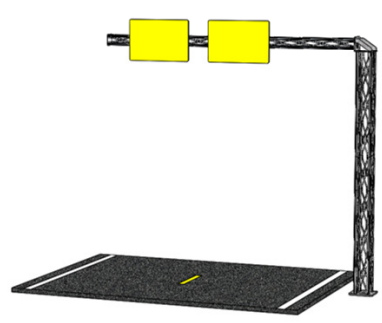

Half gantry

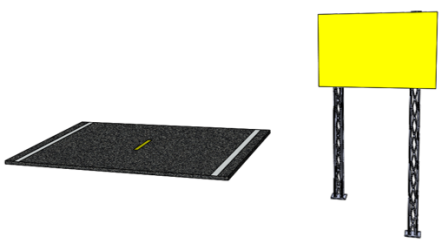

Multi signpost layout

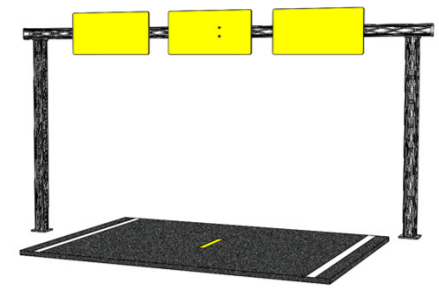

Gantry

Figure 1. Examples of road traffic products 
The current customization practice in engineering and development resembles an ETO customization. This can more or less be described as a 'copy-and-paste' approach, where preferred solutions from earlier projects are applied in new projects. Although the different deliveries have much in common, such as structural shape configuration and low volume, the variance at product detail-level is high. Consequently, significant communication and documentation effort and (re-)engineering must be done in many loops in each project to accommodate specific needs and to document the performance of the specific product solution. The information flow in the current situation can be characterized by a sequential, "over-thewall" approach" and is not straightforward, but has to processed and passed on by many stakeholders. Firstly, the public roads administration tenders infrastructure projects based on political agendas and public budgets. They also create, maintain and control valid legislation for equipment along the roadside. Thereafter, the awarding authority starts planning and building the road including all groundwork, planning, construction and setting up equipment. Usually, additional consultants are hired for the doing the traffic engineering work and proposing overall layout solutions for the traffic system. After all road planning details are defined the plans are handed to a turnkey traffic product distributor to procure all necessary equipment for the construction. One part of this is the signposting along the road. Finally, the road sign information in form of a sign-table is handed to the mast supplier (case company) for engineering of adequate mast constructions, creating documentation and giving an estimate of costs. The results are then communicated backwards to the right stakeholder - usually not the straight way, but via other stakeholders. Commonly changes occur in the planning or building process of roads, which results in a new loop of communication, reengineering and re-documentation.

Due to the present strategy, Lattix experiences several undesirable effects in their business practices, which reduce the company's competiveness. The approach is time-consuming and requires many resources for engineering that does not create value. Firstly, Lattix has few opportunities to influence or to react to the road planning and building process directly as they are the last link in the communication chain. Secondly, the company produces much waste in form of engineering and documentation that never are sold or manufactured as they either are changed and require reengineering or the award is won by a competitor. In order 'leanify' the described process Lattix desired to turn the current ETO customization strategy into a web-based CTO customization strategy, giving the configuration work directly to the stakeholders and automatizing the engineering work (Figure 2, bottom).

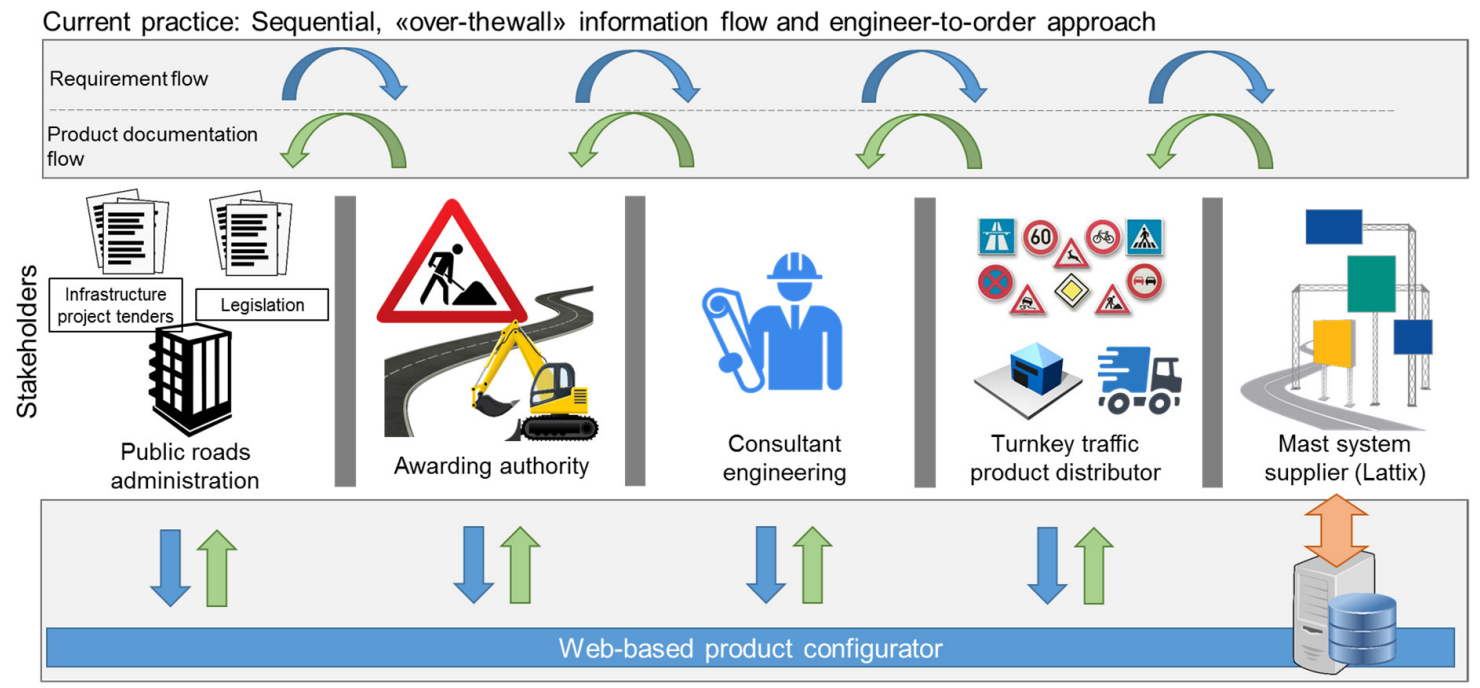

Desired practice: Direct information flow and user-driven, automized configure-to-order approach

Figure 2. Comparison of current and desired engineering approach

\subsection{Research approach}

Lovett et al. (2000) and (Ferguson et al., 2014) recommend a number of activities necessary to implement a web-based CTO approach. These recommendations have been applied as a base for implementation as summarized in Table 1. In the first phase, the entire business profile has been analyzed on the bias of data 
of the sales management system with focus on volume, production cost and potential financial gains. Further, the engineering work load has been compared to these data. In the second phase, the road traffic product portfolio has been prepared for a product customization approach. This included a mapping of the product requirements, functions, principal solutions and physical details according to product architecture modelling and systems engineering methodology and the establishment of a product platform with both integrated modular and optional modules as parts, kits and systems. Products have been re-engineered and the models have been parameterized in order to prepare them for automatic configuration.

Table 1. Research approach

\begin{tabular}{|c|c|c|}
\hline Phases & Activities & Tasks \\
\hline \multirow[t]{4}{*}{$\begin{array}{l}\text { 1. Initial } \\
\text { investigation }\end{array}$} & $\begin{array}{l}\text { - Analysis of current business } \\
\text { profile }\end{array}$ & - Analysis of data in sales management system \\
\hline & - Cost/benefits analysis & \\
\hline & - Market analysis & - Internet research of competitor products and prices \\
\hline & - Work load analysis & - Analysis of project resource use \\
\hline \multirow{2}{*}{$\begin{array}{l}\text { 2. Product and } \\
\text { manufacturing } \\
\text { preparation }\end{array}$} & - Analysis of product portfolio & - Analysis of products \\
\hline & $\begin{array}{l}\text { - Restructuring of product } \\
\text { families }\end{array}$ & $\begin{array}{l}\text { - Application of methodologies to restructure and } \\
\text { establish product architectures, platforms and } \\
\text { families }\end{array}$ \\
\hline \multirow[t]{2}{*}{$\begin{array}{l}\text { 3. Requirement } \\
\text { analysis }\end{array}$} & $\begin{array}{l}\text { - Identification of internal } \\
\text { requirements and constraints }\end{array}$ & $\begin{array}{l}\text { - Analysis of manufacturing machines and } \\
\text { capabilities }\end{array}$ \\
\hline & $\begin{array}{l}\text { - Identification of external } \\
\text { requirements and constraints }\end{array}$ & $\begin{array}{l}\text { - Analysis of stakeholders and market situation } \\
\text { - Semi-structured interviews with potential users } \\
\text { - Analysis of potential competing tools }\end{array}$ \\
\hline 4. Tool selection & $\begin{array}{l}\text { - Hardware and software } \\
\text { investigation }\end{array}$ & $\begin{array}{l}\text { - Analysis of software tool specification at the market } \\
\text { - Analysis of company internal software }\end{array}$ \\
\hline \multirow[t]{5}{*}{ 5. Implementation } & $\begin{array}{l}\text { - Knowledge capture and } \\
\text { structuring }\end{array}$ & - Interviews with chief engineer \\
\hline & - Functional design & - Implementation of the results gathered above \\
\hline & - User interface design & - Frequent design reviews with responsible engineer \\
\hline & - Data design & \\
\hline & - Coding & \\
\hline \multirow[t]{2}{*}{ 6. Verification } & - Testing & - Testing procedure with test users \\
\hline & - Training & $\begin{array}{l}\text { - Presentation of results for the stakeholders, } \\
\text { interviews with users }\end{array}$ \\
\hline
\end{tabular}

The third phase started with an identification and mapping of the stakeholders and information flow (Figure 2). Further, potential users at the stakeholders were interviewed to identify current work patterns, experiences with current tools and expectations to a customized interface. Moreover, current standards for road safety equipment, calculation rules and wind load calculation have been analyzed. The results were summarized in requirements and constraints of all external factors. In addition, the company-internal requirements and constraints have been identified. By interviewing engineers and factory workers as well as gathering capabilities of the manufacturing equipment rules for possible product configurations could be defined. To implement the customization approach 3D feature-based, parametric modelling needed to be applied along with software-based mechanical analyses in a web-based system. Since the case company already used SolidWorks (SW) in their design process, DriveWorks Pro (DW) was selected as the main tool in the CTO framework; it is also compatible with SW. DW also enables both the automatization of design tasks as well as tools for a web-based interface. The implementation phase has been performed by applying the editor of DW with integrating MS Office tools for documentation. In DW, the functional design, logical flow and user interfaces have been established accompanied with coding and data design. Rules and constraints for product configuration have been implemented according to the results gathered before supplied with continuous feedback of the chief engineer. Rules for mechanical calculations and 
documentation have been implemented in MS Excel files. The implementation of sub-functions were tested iteratively during implementation. After the implementation of the entire system was complete, engineering students served as pilots to test the result and identify bugs. As the system became more mature, tests were performed among customers and improvements were made based on their feedback. Data have been gathered by applying semi-structured interviews, which were conducted distributed over the entire implementation phase (step 1-6 in Table 2) over a period of two years. Among the interviewees were different roles as two of the case company's engineers, a company's sales responsible and CEO, two different customers and several testers. Questions were related to functional needs and expectations, timeuse before and after implementation, confidence into the system, product presentation, maintenance and operation effort and cost, perceived benefits and challenges as well as overall satisfaction. The answers to questions and results of emerged discussions have been recorded and analyzed to identify commonalities and differences between different perspectives of the roles and between expectations and implementation results before, during and after implementation.

\section{Results}

\subsection{Product portfolio preparation and product models}

The backbone of all products (Figure 1) are the four different aluminum profiles, which were restructured into five different product families. All masts are characterized by a square cross-section and a lattice structure at each side. The difference between the masts is the feed size and the geometry of the lattice structure. The lattice structure provides the advantage of a lightweight mast, which is stiff on the one hand, but still energy-absorbing in case of a car crashing into it. However, this structures entail some constraints to the manufacturing process. Since the lattice structure only can be produced as complete (closed) lattices, the mast length is dependent on the recurrence of the geometry. In other words, each mast is built of a number of integrated geometrically equal lattice modules. The lattice structure is produced by slotting extruded aluminium profiles, followed by a stretching process. Consequently, the masts need to be produced in integrated modules with predefined standard lengths. In order to meet a certain customer need, the masts can be combined arbitrary, according to the necessary strength and required displacement limit. To connect and assemble the masts, the company provides base plates, connectors and top plates. This way, the products can be customized by applying modularity. In order to preserve intellectual property of the 3D-models and geometrical details, the original 3D models have been simplified. The important outer dimensions and appearance, however, were not changed. In addition this also reduced the computing time and data storage place and thus increased system stability. These models have been parameterized in generic SW assembly files and are controlled by algorithms in DW and saved in the PLM database.

\subsection{Documentation}

The documents required by the stakeholders are sales and marketing documents, bill of materials, product drawings, strength analysis and analysis of input loads based on national standards. To create those documents, generic templates in MS Word and Excel have been created. The generic templates are saved in a databased and filled with specific information when required. In MS Word the templates consist of empty boxes, which are filled with text, numbers or figures. In MS Excel the same templates can be used both for documentation and calculation. When used for pure calculation tasks, variables are exported from the DW interface, processed by rules in Excel and reimported to DW. As sheets can be hidden in the Excel file they are not visible for the users after the PDF conversion, the same files can be used for both calculation and providing a customer view of the results. All documents are converted to PDFs and stored into the database, together with the source files, whereas only the PDFs are visible to the users.

\subsection{Product configuration}

The result of the implementation is summarized in Figure 3. Road projects are usually arranged into certain road sections where sign position and types are summarized in a sign table. The input of this table is necessary for dimensioning and configuring mast constructions. Due to the fact that there are 
different stakeholders with different needs, specific user teams with individual views have been defined. For instance, contracted customers get quote based on a different price list than non-contracted, or a wind load configuration based on another national standard. Each user has the possibility to either start new projects or edit existing ones in a project history.

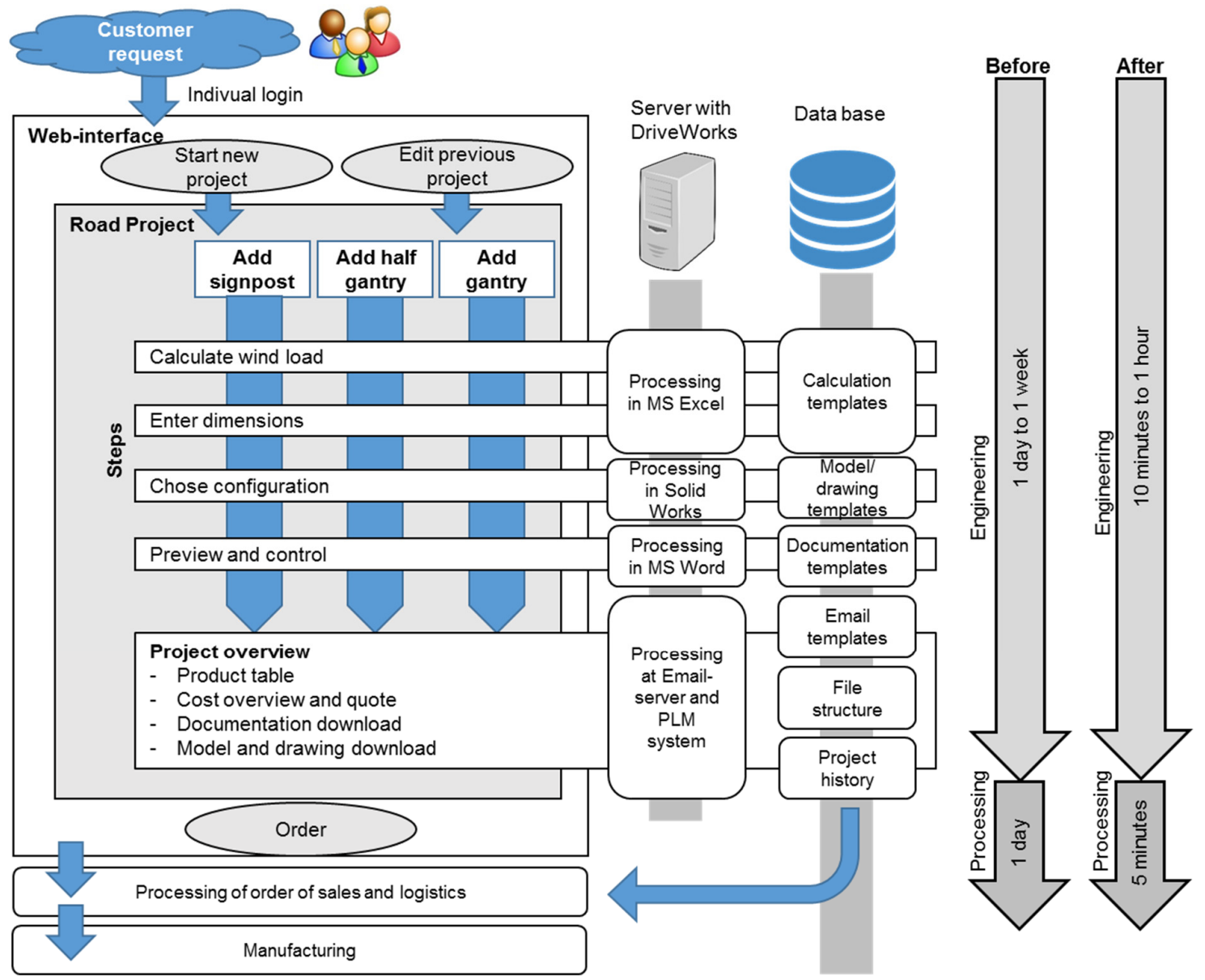

Figure 3. Product configuration and information processing overview

To start a new configuration, the user starts a new project, where signposts, half gantries or gantries can be added independently and in arbitrary number. The configuration starts with a definition of external mechanical loads. Based on the geographical location, reference wind load is calculated based on tables from national standards the recommend wind loads dependent statistics on height above sea level, reference height above terrain, placement in the country, etc. The input data is processed in Excel sheets and returned to the web-interface. Secondly, the user needs to define the desired dimensions. Basic data are sign size and height above road, but also additional information about placement in relation to the road shoulder, or constraints to desired deflections, or expected snow plough speed can be added by the user to get a more detailed design recommendation. In the next step the input data are processes in Excel again and based on user input, manufacturing and geometry constraints a configuration is recommended to the user. Often several configurations are possible. For instance a large traffic sign may be supported by three smaller sign post sections or two larger ones to gain suitable design solutions. Here, the user has to decide which solutions suit the specific case. The user gets immediate feedback on cost and mechanical utilization for each variant, such that there is a transparent and direct communication of possibilities, constraints and consequences. Finally, the user needs to confirm the own input and can get a 3D preview, if desired. When saved, the product is added to the project list.

Repeating the described steps, all sign post positions can be added to the project list until the road section is entirely defined. Based on all input, the user can get a quote for the whole project and download the 
desired documentation, which is created by the integration of Solid Works and MS Office in the background. The user can then either save the project and edit it at a later point of time or send an immediate order directly to the sales office.

The described process shows to reduce the configuration time significantly as illustrated on the right side of Figure 3. Instead of days or weeks, the configuration of products can now be done in minutes or hours.

\section{Discussion}

The experiences of the case company are summarized in Table 2. Beside the challenges that are expected with this kind of approach, like the initial investment cost, additional software and operation cost or the preserving of intellectual property, and the required combination of engineering and IT competency, there were some issues that were not expected. A major, rather unexpected, challenge was to build up confidence among the users. It was observed that even though the used pretended that the system was easy to use, many of them continued working in previous patterns. One reason is that the market for road safety equipment is rather conservative, with static structures from formerly state-owned companies with related routines and working patterns from the past. Thus, renewals or changes are met with high scepticism and resistance, especially among the more experienced employees. It was experienced that younger employees are easier to motivate to use this system. Another reason for not using the system was that the traffic consultants felt not comfortable making own configuration decisions as they felt that they take more responsibility. Even though the system is constrained in a way that unsuitable solutions are avoided, the users felt a higher ownership and related responsibility to the output. Thus, further effort in creating user acceptance is required.

Table 2. Experienced challenges and benefits

\begin{tabular}{|c|c|}
\hline Challenges & Explanation \\
\hline Initial investment & High work load in analyzing the situation and establishing a framework \\
\hline Additional operating cost & Maintenance and operation of data system and data storage \\
\hline Additional software cost & Additional software licenses required \\
\hline $\begin{array}{l}\text { Additional updates and } \\
\text { maintenance }\end{array}$ & $\begin{array}{l}\text { On product updates, changes in legislation or other the system needs to be } \\
\text { updated }\end{array}$ \\
\hline $\begin{array}{l}\text { Establishment of customer } \\
\text { confidence }\end{array}$ & Customer needs to trust the system that the input is correct \\
\hline $\begin{array}{l}\text { Increased perceived user } \\
\text { responsibility }\end{array}$ & $\begin{array}{l}\text { Customers can feel responsible for the output and can feel uncomfortable } \\
\text { with it }\end{array}$ \\
\hline $\begin{array}{l}\text { Far-ranging consequences of } \\
\text { system mistakes }\end{array}$ & $\begin{array}{l}\text { Mistakes in the system or rules may create product configurations that are } \\
\text { nor suitable }\end{array}$ \\
\hline $\begin{array}{l}\text { Preservation of intellectual } \\
\text { property }\end{array}$ & $\begin{array}{l}\text { Output information needs to be selected carefully to not share details of } \\
\text { intellectual property }\end{array}$ \\
\hline Benefits & Explanation \\
\hline Immediate response & $\begin{array}{l}\text { Customer gets immediate feedback on input, possible configurations and } \\
\text { cost }\end{array}$ \\
\hline Automatic export of 3D models & Customers can get 3D models for BIM-road models immediately \\
\hline Direct and fast communication & $\begin{array}{l}\text { Customers can get desired information directly instead of pushing the } \\
\text { request through a long chain of stakeholders }\end{array}$ \\
\hline Better transparency & Transparent cost calculation and product system dependencies \\
\hline Improved customer view & $\begin{array}{l}\text { Customers get the information customized for their specific price list and } \\
\text { required information level or file type }\end{array}$ \\
\hline Waste elimination & $\begin{array}{l}\text { The automatic processing of input data into drawings and documentation } \\
\text { reduces the waste of workload on configurations that were not used, no } \\
\text { repeated problem solving, less rework }\end{array}$ \\
\hline Improved sales support & Configuration tool is used by sales to make quotations \\
\hline Overall increased competiveness & Faster configuration and reduced engineering work load \\
\hline
\end{tabular}


Among the benefits the expected advantages of reduced engineering waste, more direct and faster communication and increased competiveness could be observed. A major, more unexpected benefit was observed from Lattix' internal sellers actually became the most frequent users of the system as it automatically creates sales documentation with illustrations and 3D models with related quotes. This documentation is used as support as sales can create quotes that users can view when logging in to their account. Another advantage that probably will increase competiveness in the future is that the 3D models can be exported in different file formats, which make the system compatible with 3D road planning and so-called Building-Information Modelling (BIM). This trend, where all road construction and equipment information are digitalized, is observed at engineering consultant and construction companies to accelerate the road planning process, reduce cost and increase quality. Thus the product information is more transparent and customer's get a better understanding of the product and an immediate response how Lattix' products fit into the entire infrastructure project.

\section{Conclusions}

This paper presents how a web-based solution for customization of safe mast constructions has been implemented in a SME with relatively simple tools. The DW web-interface guiding the configuration process is linked to parameterized 3D CAD models in SW, and all calculation and documentation efforts can be supported by common MS Office software tools. The web-based mast configuration and guided selling features support the companies own teams, distributors and other stakeholders, and shorten the respond time to customer enquiries and manufacturing from days or weeks to minutes or hours. In addition, the transparency of cost and product configuration dependencies is increased significantly. The configuration work can be handed to customers and engineering resources can be used for improving products instead of reinventing them. However, the operation of the customization framework is still in its starting phase and it remains to be improved and analyzed in terms of long-term organizational effect. One issue that should be examined further is to how to motivate the users to use the system more actively, and how to create more confidence in the system. Further, the system should be improved in a way that it can directly export 3D models into road planning tools of construction companies and engineering consultants. Another effort is to integrate manufacturing processes into the configurator and make a direct data transfer between the order and the manufacturing process.

\section{References}

Agard, B. and Basetto, S. (2012), "Modular Design of Product Families for Quality and Cost", International Journal of Production Research, Vol. $51 \quad$ No. 6, pp. 1648-1667. https://doi.org/10.1080/00207543.2012.693963

Barros, M., Duarte, J. and Chapparo, B.M. (2014), "Integrated Generative Design Tools for the Mass Customization of Furniture", In: Gero, J.S. (ed.), Design Computing and Cognition '12, Springer Netherlands. https://doi.org/10.1007/978-94-017-9112-0_16

Berry, C., Wang, H. and Hu, S.J. (2013), "Product architecting for personalization", Journal of Manufacturing Systems, Vol. 32 No. 3, pp. 404-411. https://doi.org/10.1016/j.jmsy.2013.04.012

Bruun, H.P.L., Mortensen, N.H. and Harlou, U. (2013), "Interface Diagram: Design Tool for Supporting the Development of Modularity in Complex Product Systems", Concurrent Engineering, Vol. 22 No. 1, pp. 6276. https://doi.org/10.1177/1063293x13516329

Chapman, C.B. and Pinfold, M. (1999), "Design Engineering-A Need to Rethink the Solution Using Knowledge based Engineering”, Knowledge-Based Systems, Vol. 12 No. 5-6, pp. 257-267. https://doi.org/10.1016/S09507051(99)00013-1

Da Cunha, C., Agard, B. and Kusiak, A. (2007), "Design for Cost: Module-Based Mass Customization", Automation Science and Engineering, Vol. 4 No. 3, pp. 350-359. https://doi.org/10.1109/TASE.2006.887160

Davis, S.M. (1989), "From “future perfect": Mass customizing”, Planning Review, Vol. 17 No. 2, pp. 16-21. https://doi.org/10.1108/eb054249

Dietrich, A.J., Kirn, S. and Sugumaran, V. (2007)," A Service-Oriented Architecture for Mass Customization; A Shoe Industry Case Study", IEEE Transactions on Engineering Management, Vol. 54 No. 1, pp. 190-204. https://doi.org/10.1109/TEM.2006.889076

Duray, R., Ward, P.T., Milligan, G.W. and Berry, W.L. (2000), "Approaches to mass customization: configurations and empirical validation”, Journal of Operations Management, Vol. 18 No. 6, pp. 605-625. https://doi.org/10.1016/S0272-6963(00)00043-7 
Ferguson, S.M., Olewnik, A.T. and Cormier, P. (2014), “A review of mass customization across marketing, engineering and distribution domains toward development of a process framework", Research in Engineering Design, Vol. 25 No. 1, pp. 11-30. https://doi.org/10.1007/s00163-013-0162-4

Fogliatto, F.S., Da Silvera, G.J.C. and Borenstein, D. (2012), “The mass customization decade: An updated review of the literature", International Journal of Production Economics, Vol. 138 No. 1, pp. 14-25. https://doi.org/10.1016/j.ijpe.2012.03.002

Forza, C. and Salvador, F. (2007), “Application support to product variety management”, International Journal of Production Research, Vol. 46 No. 3, pp. 817-836. https://doi.org/10.1080/00207540600818278

Grenci, R.T. and Watts, C.A. (2007), "Maximizing Customer Value via Mass Customized e-consumer Services", Business Horizons, Vol. 50 No. 2, pp. 123-132. https://doi.org/10.1016/j.bushor.2006.08.006

Gunasekaran, A. (1998), "Agile Manufacturing: Enablers and an implementation framework", International Journal of Production Research, Vol. 36 No. 5, pp. 1223-1247. https://doi.org/10.1080/002075498193291

Haug, A., Lisberg, T. and Hvam, L. (2008), "A software tool for design and documentation of configurator knowledge bases”, Mass Customization Services, DTU Management., pp. 199-218.

Holland, J.H. (1992), Adaptation in Natural and Artificial Systems, Cambridge, MA, MIT Press.

Hu, S.J. (2013), "Evolving Paradigms of Manufacturing: From Mass Production to Mass Customization and Personalization", Procedia CIRP, Vol. 7, pp. 3-8. https://doi.org/10.1016/j.procir.2013.05.002

Jiao, J., Ma, Q. and Tseng, M.M. (2003), “Towards high value-added products and services: mass customization and beyond", Technovation, Vol. 23 No. 10, pp. 809-821. https://doi.org/10.1016/S0166-4972(02)00023-8

Kennedy, B.M., Sobek, D.K. and Kennedy, M.N. (2013), "Reducing Rework by Applying Set-Based Practices Early in the Systems Engineering Process", Systems Engineering, Vol. 17 No. 3, pp. 278-296. https://doi.org/10.1002/sys.21269

Kristianto, Y., Helo, P. and Jiao, R. (2013), "Mass customization design of engineer-to-order products using Benders' decomposition and bi-level stochastic programming”, Journal of Intelligent Manufacturing, Vol. 24 No. 5, pp. 961-975. https://doi.org/10.1007/s10845-012-0692-Z

Kumar, R. and Allada, V. (2007), "Function-technology-based Product Platform Formation", International Journal of Production Research, Vol. 45 No. 24, pp. 5687-5714. https://doi.org/10.1080/00207540600806380

Kuroda, M. and Mihira, H. (2007), "Strategic Inventory Holding to Allow the Estimation of Earlier Due Dates in Make-to-order Production" International Journal of Production Research, Vol. 46 No. 2, pp. 495-508. https://doi.org/10.1080/00207540601138486

Kusiak, A. and Huang, C.-C. (1996), "Development of Modular Products", Components, Packaging, and Manufacturing Technology, Vol. 19 No. 4, pp. 523-538. https://doi.org/10.1109/95.554934

Levandowski, C.E., Corin-Stig, D., Bergsjö, D., Forslund, A., Högman, U. et al. (2013), “An integrated approach to technology platform and product platform development", Concurrent Engineering, Vol. 21 No. 1, pp. 6583. https://doi.org/10.1177/1063293X12467808

Lovett, P.J., Ingram, A. and Bancroft, C.N. (2000), "Knowledge-based engineering for SMEs — a methodology", Journal of Materials Processing Technology, Vol. 107 No. 1-3, p. 384-389. https://doi.org/10.1016/S09240136(00)00728-7

Martin, M.V. and Ishii, K. (2002), "Design for Variety: Developing Standardized and Modularized Product Platform Architectures", Research in Engineering Design, Vol. 13 No. 4, pp. 213-235. https://doi.org/10.1007/s00163-002-0020-2

Meyer, M.H. and Lehnerd, A.P. (1997), "The power of product platforms - Building Value and Cost Leadership", Journal of Product Innovation Management, Vol. 14 No. 6, pp. 526-529, New York, The Free Press. https://doi.org/10.1016/S0737-6782(97)80157-9

Mintzberg, H. (1988), "Generic strategies: toward a comprehensive framework", Advances in strategic management, Vol. 5, pp. 1-67.

Park, J. and Simpson, T. (2005), "Development of a Production Cost Estimation Framework to Support Product Family Design", International Journal of Production Research, Vol. 43 No. 4, pp. 731-772. https://doi.org/10.1080/00207540512331311903

Perrouin, G., Acher, M., Davril, J.M., Legay, A. and Heymans, P. (2016), "A Complexity Tale: Web Configurators", IEEE/ACM 1st International Workshop on Variability and Complexity in Software Design (VACE), May 15, 2016, pp. 28-31. https://doi.org/10.1109/VACE.2016.014

Piller, F. (2004), "Mass Customization: Reflections on the State of the Concept", International Journal of Flexible Manufacturing Systems, Vol. 16 No. 4, pp. 313-334. https://doi.org/10.1007/s10696-005-5170-x

Pine, B.J. (1993), "Making mass customization happen: Strategies for the new competitive realities", Planning Review, Vol. 21 No. 5, pp. 23-24. https://doi.org/10.1108/eb054435

Robertson, D. and Ulrich, K. (1998), "Planning for Product Platforms", Sloan Management Review, Vol. 39 No. 4, pp. 19-31. 
Salvador, F., Rungtusanatham, M. and Forza, C. (2004), "Supply-chain Configurations for Mass Customization", Production Planning \& Control, Vol. 15 No. 4, pp. 381-397. https://doi.org/10.1080/0953728042000238818

Sanchez, R. (2004), “Creating Modular Platforms for Strategic Flexibility”, Design Management Review, Vol. 15 No. 1, pp. 58-67. https://doi.org/10.1111/j.1948-7169.2004.tb00151.x

Stone, R.B., Wood, K.L. and Crawford, R.H. (2000), "A Heuristic Method for Identifying Modules for Product Architectures”, Design Studies, Vol. 21 No. 1, pp. 5-31. https://doi.org/10.1016/S0142-694X(99)00003-4

Dr.-Ing. Sören Ulonska

Lattix AS, Research and Development Department

Baker Østbys Vei 5, 1351 Rud, Norway

Email: soren.ulonska@lattix.net 